\title{
The Effectiveness of Different Methodologies in Gathering Information for Developing BIM Models to Support the Operation and Maintenance of Existing Buildings
}

\author{
S. O. Álvarez-Romero, J. A. González-Fajardo, J. N. Zaragoza-Grifé, S. A. Audeves-Pérez \\ School of Engineering, Autonomous University of Yucatan, Mérida, México \\ Email: aromero@correo.uady.mx, antonio.gonzalez@correo.uady.mx
}

How to cite this paper: Álvarez-Romero, S.O., González-Fajardo, J.A., Zaragoza-Grifé, J.N. and Audeves-Pérez, S.A. (2018) The Effectiveness of Different Methodologies in Gathering Information for Developing BIM Models to Support the Operation and Maintenance of Existing Buildings. Journal of Building Construction and Planning Research, 6, 298-316.

https://doi.org/10.4236/jbcpr.2018.64020

Received: November 9, 2018

Accepted: December 21, 2018

Published: December 24, 2018

Copyright (c) 2018 by authors and Scientific Research Publishing Inc. This work is licensed under the Creative Commons Attribution International License (CC BY 4.0).

http://creativecommons.org/licenses/by/4.0/

\section{Open Access}

\begin{abstract}
Systematic, preventive and corrective maintenance is essential for existing buildings in order to retain their original functionality and appearance and satisfy the needs of the users. Essential input for maintenance is information about buildings. This paper discusses the assessment of the advantages and limitations of using photogrammetry and a low-cost 3D scanner to collect information from existing buildings and create, through integrative software, BIM models as information systems to support the operation and maintenance functions. Also, these methodologies were compared with one another as well as with a manual information survey conducted at a university campus. The main conclusion is that a combination of methods must be used to obtain geometrical information on existing buildings for their operation and maintenance functions, depending on which ones are the most suitable for the case at hand.
\end{abstract}

\section{Keywords}

Photogrammetric Surveying, 3D Scanner Surveying, BIM, Building Operation and Maintenance

\section{Introduction}

The built infrastructure life cycle can be visualized in five stages: planning, design, construction, operation, and final disposal; the operation stage includes maintenance, and it is the longest stage and the one that contributes the most to the final building cost [1]. Maintaining a building extends its useful life, and is 
achieved by protecting and restoring its damaged items during their use or by exposure to environmental actions. Maintaining a building with adequate spaces to support the activities it hosts, directly impacts the productivity of such activities [2]. All buildings are always exposed to damage and deterioration, and despite this, they must preserve the original appearance and satisfy the needs of the users [3]. However, despite the importance of maintenance, this is not done systematically in developing countries, and there is a lack of foresight regarding their related costs [4]. Maintenance is, in most of the cases, of corrective type and very little is of preventive type.

Primary input for maintenance is information about buildings [5]. This information includes drawings, specifications, warranties, operation manuals and the current state of the buildings and their systems. The facility manager gets this information from the builder in the information package that is commonly delivered to him along with the building. Afterward, it is the responsibility of operation and maintenance manager to keep this information organized, updated and available, but given the scarcity of resources, these are usually assigned to the direct costs of the operation and maintenance itself, and not to the information management.

In a paradox, having organized and updated information reduces operating costs since it makes the task easier to accomplish; at the same time, it reduces the waiting times for understanding the problem and obtaining the information needed for providing the maintenance [6].

\subsection{Using Building Information Modeling (BIM) as a Support for Operation and Maintenance Functions}

People in charge of facilities management are continually facing the challenge of improving the quality and standardizing the information they have at their disposal, with the primary purpose of satisfying the daily needs of operation, while providing the owners with reliable information on the assets for their proper management [7]. BIM has positioned itself to offer a new level of functionality in the management of buildings and related assets, which is motivating companies to start adopting BIM to support the operation and maintenance process.

The above approach was mainly driven by the COBie project initiated in 2005 by The Facility Maintenance and Operations Committee of the National Institute of Building Sciences. COBie standard (Construction-Operations Building Information Exchange) defines the assets information that is delivered as part of a construction project and is used to document all data for the BIM process. The COBie specifications and guidelines combine industry knowledge and best practices. COBie pilot standard was released in 2007; in 2011 it was approved by the National Institute of Building Sciences (NIBS) as part of its National Building Information Model Standard (NBIS-US) standards model. COBie will be able to provide the structure in the short term to easily transfer information from BIM applications to building management systems [8].

Universities are rapidly advancing in the implementation of BIM for support- 
ing operation and maintenance of their infrastructure. A notable example is the case of the School of Medicine at the University of Massachusetts, where the Albert Sherman Center was recently completed. The facility is an eleven-story building, nine occupied and the last two containing mechanical systems; it is a $48,000 \mathrm{~m}^{2}$ building [9]. This project was developed with the vision of using BIM beyond design and construction, incorporating it for facility planning, operations and maintenance. In this case a model is integrated into the current facilities building management system, the model is a full spatial as-built; includes the design and actual capacity of the building systems; contains assets tagging; has the ability to isolate a system and; has a database for the non-graphical documentation linked to the model. The model is managed through commercial software Autodesk Navisworks ${ }^{\circledR}$ and integrates eleven files of different models coordinated in a single visible file. This software is also used to query the building model and retrieve information associated with building components. This solution uses the SharePoint software as the container of non-graphic information (warranties, specifications, and operation and maintenance manuals) which is associated with the objects of the model; therefore, the retrieval of such information can be achieved by querying the coordinated model.

\subsection{Developing BIM Models}

This research focuses on the incorporation of BIM to support the operation and maintenance of buildings. BIM models should make the corrective and preventive maintenance easier, as well as keeping the building information organized, updated and available.

Authoring a BIM model of an existing building requires having real dimensions of elements. Traditionally, information about these dimensions is obtained through an architectural survey. This approach includes a set of operations, measurements, and analysis necessary to understand and document architectural assets of a building, referred to its urban context, dimensional characteristics, historical complexity, structural and constructive characteristics, as well as to its form and function [10].

The architectural survey is usually performed with measuring tape and other measuring devices, but it is a costly task as it requires much time and effort. This task may be performed more easily if the layout and geometrical information of the building is extracted from a point cloud; nowadays, this point cloud can be acquired through 3D laser scanners or other available technologies [11]. A point cloud offers significant advantages since it constitutes a faithful representation of the building; the dimensions of the elements can be verified as required. In addition, the point cloud can be imported into the BIM modeling environment and used as a reference to create a three-dimensional model.

In this research, two techniques were evaluated for the construction of geometrical information of buildings through the generation of point clouds; subsequently, they were compared with one another, as well as with the manual arc- 
hitectural survey. The techniques evaluated to create point clouds were photogrammetry and the use of a low-cost 3D laser scanner. The manual architectural survey was used as a benchmark for accuracy comparison.

\subsection{Using Photogrammetry}

Photographs are essential for photogrammetric measurement. High reliability, precision, and automation of the photogrammetric process are directly proportional to the quality of the photographs used. Photogrammetry, in its broadest sense, reverses the photographic process, transforming or mapping three-dimensional information from a two-dimensional image [12]. However, because a portion of information is lost in the photographic process, it is not possible to reconstruct all the information using a single photograph. At least a couple of photographs of the same object are required; they must be taken from different angles and, even so, only is possible to retrieve information from the sections of the object appearing in more than one photograph. Additionally, the general process of photogrammetry is far from perfect in practice, partly because the premises of metrology are not always given, which assumes clear objects, with defined edges and contrasts and without reflections.

Photogrammetry uses the basic principle of triangulation, whereby the location of a point in its three-dimensional coordinates is calculated by finding the intersection of lines in space. However, to triangulate points using photographs, the position of the camera and the angle of its point of view must also be known. The re-sectioning technique is used to determine these parameters [12].

\subsection{Using Low-Cost 3D Scanners}

One objective of this research was to test a low-cost 3D scanning device, to be used by schools and universities in developing countries. Low-cost 3D scanners differ from 3D laser scanners in the sensor technology; in place of laser sensors, they use sensors of structured light, visible light, motion, and stereoscopy, which allow them to capture three-dimensional information from scanned objects. Structured light entails projecting a pattern of infrared light, usually a grid, onto the surface of objects; the projection deformed by the contour of the objects is recorded by a camera, which analyzes it to understand and interpret the three-dimensional shape of the object. Stereoscopy allows overlapping points captured by two cameras to be identified, and with triangulation and re-sectioning techniques, coordinates of these points are determined. This technology uses motion sensors to determine the distance to the points and their scale so that the point clouds produced with these devices are scaled [13]. The limitation with manual equipment is the sensor's range, which when mounted on manual devices is around $4 \mathrm{~m}$, which is the maximum distance that the object can be from the scanner. Another limitation of these devices is that the main sensor works with infrared light, which inhibits its use outdoors since sunlight saturates this type of sensors. For this research, a device which offers mobility in crowded 
spaces, such as mechanical rooms, was selected; tripod based scanners and two-person operated scanners where ruled out. Low-cost scanners cost 5 to 10 percent of the price of the industrial grade scanners.

\section{Methodology}

The proposed objective of this research was to evaluate the benefits and limitations of the use of photogrammetry and a low-cost 3D scanner, to gather information from existing buildings and to create a BIM model based on this data. These two methodologies were compared with each other, as well as with a traditional surveying method.

\subsection{Photogrammetry for Surveying of Existing Buildings}

\subsubsection{Evaluation of Photogrammetry Equipment}

As explained, photogrammetry has a photographic component and a metrological component. In this research, the photographic component is in the hands of the photographer, therefore, precision and quality may depend on the equipment used.

Metrology is performed by the software used to process the images, and although each software tool has different ways to perform triangulating or re-sectioning, most produce similar results. Photogrammetry software typically does not allow control over the triangulation and re-sectioning methods because these are part of the proprietary algorithm of the software vendor. This kind of software applications allows limited control over how the photographs are processed.

Given the complexity of taking a photograph to produce reliable results with adequate accuracy, three kinds of cameras were tested in this study.

- Digital SLR camera (DSRL) model Nikon D5300, with $23.5 \mathrm{~mm} \times 15.6 \mathrm{~mm}$ sensor, and 24 megapixels, with an AF-P DX Nikkor lens of $18-55 \mathrm{~mm}$ focal length and a maximum aperture of f/3.5 - 5.6 and minimum of $\mathrm{f} 22$ - 38 and stabilizer.

- The iPhone SE camera, with sensor of $4.8 \mathrm{~mm} \times 3.6 \mathrm{~mm}, 12$ megapixels, equivalent focal length of $29 \mathrm{~mm}$ and fixed aperture of $\mathrm{f} / 2.2$.

- GoPro Hero4 Silver edition, $5.37 \mathrm{~mm} \times 4.04 \mathrm{~mm}$ sensor, 8 megapixels, focal length equivalent to $17.2 \mathrm{~mm}$, and aperture of $\mathrm{f} 2.8$.

Two computational applications were used in this investigation:

- Agisoft Photoscan, version 1.3, which is a software capable of exporting point cloud files to standard formats, among which is the PTS format.

- Autodesk Recap 360, version 2017, which is software located in the cloud of the design software developer Autodesk, which still produces the standard PTS point cloud file.

\subsubsection{Recommended Techniques for Taking Pictures}

Photographs do not always produce a usable point cloud. Based on recommendations from various sources and software documentation [14], it was possible 
to determine suitable techniques for taking photographs that usually produce a usable point cloud.

For building exteriors, such as a facade, the process that produced the best results was when the camera position is perpendicular to the building surface as shown in Figure 1.

During the practice sessions of this research, the best results were obtained when there was an overlap of $50 \%$ or more between adjacent photographs. Also, better results were obtained by first taking a lower horizontal strip and then making the upper ones.

When allowed to photograph the entire building, a radial camera shot is recommended, taking a photograph every $5^{\circ}\left(\right.$ at $\left.10^{\circ}\right)$, always having the center of the building in the center of the photograph as shown in Figure 2.

Also, for this scenario, it is recommended to make a strip of horizontal photos until the entire perimeter is covered, overlapping photographs by $50 \%$, then continue with the upper bands until completing the shot of the building.

Indoor photograph shots are the most complex to achieve, given that these places commonly contain obstacles. In general, it is recommended to follow the pattern shown in Figure 3.

Whenever possible, in this technique, shots should be made by standing on one edge of the room and making the shot towards the opposite edge, aligned to an imaginary line that passes through the center of the room. It is advisable first to make the upper strip that includes the union of the walls with the ceiling, and then the lower strips up to the one that takes the union of the walls with the floor. Then the roof should be continued, taking concentric strips of the roof edge towards the center of the roof, and finally the floor, in the same approach as

WIIIIIIIIIIIIIIIIIIIIIIIIIIIIIIIIIIIIIIIIIIIII

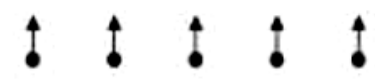

Figure 1. Camera shots for a building facade [14].

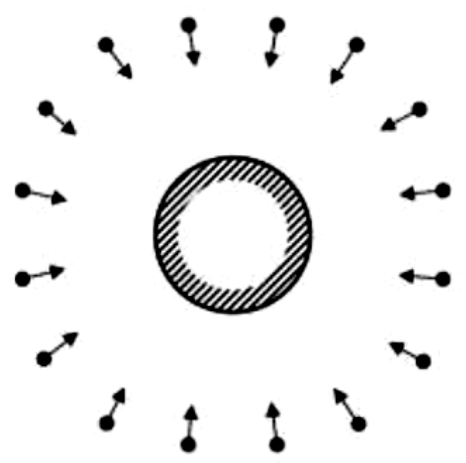

Figure 2. Camera shots for the entire building [14]. 


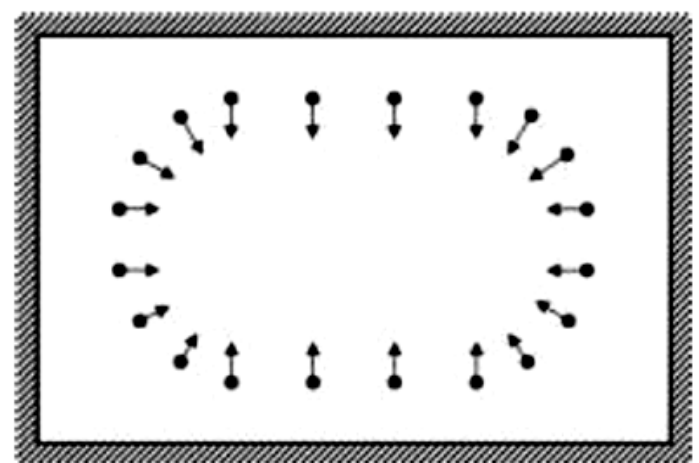

Figure 3. Camera shots for building indoors [14].

the roof, as far as obstacles allow. On the floor there are often areas that cannot be taken radially; for these areas, it is recommended that they be photographed and processed independently and then join the two or more produced point clouds.

In regards to lighting, fixed artificial lighting was used for interiors; in most cases, the installed building lighting devices were used. Natural lighting was used for exteriors; the best results were obtained with cloudy conditions, while sunny conditions required more post-processing work.

Finally, it should be mentioned that reflecting objects such as glass or metal objects produce errors in the point cloud because the software does not detect the surface of these elements, but rather the reflected objects. Reflection causes "noise" to appear in the point cloud, instead of the object. To avoid noisy photographs is advisable to cover this type of objects with paper.

\subsubsection{Scaling for Developing BIM Models}

To be able to use the point cloud, the scale of the point cloud should be adjusted. Nowadays, photogrammetry, through photographs taken with conventional photographic equipment, lacks the sophistication of a specialized photogrammetric camera that, through geo-positioning and measurement through infrared sensors, can determine the scale of objects. Without this functionality, the scaling must be done manually, by post-processing of the point cloud.

Most photogrammetric software supplements this feature by including physical scales in the scene, which are recognized by the software and help the scaling of the point cloud. However, in the case of large buildings, it is difficult to place these scales in the building in the proper way to determine the precise scale of the objects. While it is advisable to use scales, it is not always practical to do so. In this research an alternative method was tried, the point cloud was left without scale and once imported into the BIM modeling software, the point cloud was scaled using some known dimension of the building and applying a simple proportion rule; with this method, acceptable results were obtained.

Once the point cloud was scaled, the process of developing the BIM model was relatively easy for a basic experienced modeler, using the point cloud as a reference. 


\subsubsection{Photogrammetric Method for Surveying Existing Buildings}

Teams of two people were formed, composed of students of Civil Engineering of the School of Engineering at the Autonomous University of Yucatan (UADY). The survey of three university buildings was carried out as mentioned in Table 1.

The workflow for this technique consisted of the following stages:

- Photo shooting.

- Photographs processing.

- Point cloud calibration.

- BIM Model development.

Photographs were taken following the recommendations described in section 2.1.2. The building's exterior was entirely photographed, but it was not possible to take all photo shots for indoor spaces. Therefore, the results are an extrapolation of collected data from the building spaces where it was indeed possible.

After several tests of the two mentioned software for photographs processing, it was decided to use the Agisoft Photoscan, because it offered significant additional control over the processing; it allowed splitting the photoset into subsets and produce "chunks" of the building, which then can be joined; this reduced the processing time and increased the accuracy of the point cloud. A computer with a Xeon processor and Quadro 2000 video card and 16 GB of RAM was used.

Point cloud calibration was carried out in two stages; the first was noise and overlapped surfaces cleaning, using Autodesk Recap 360 software; the second was to import into Revit software, where point cloud was scaled with a reference dimension.

Autodesk Revit software was used for model creation using the point cloud just as a reference; there was no attempt to create building components from the point cloud automatically. Instead, point cloud sections in plan views and section views were used to create the building elements, snapping to the recognized planes, edges, and vertices of the point cloud. Regardless this approach is a non-automated process in Revit, the use of the imported point cloud greatly facilitates the creation of the model; the beginner level modelers, who created the BIM models, found no significant issues during the creation process. Floor plan views of the model were created to match the deliverable with the one that was elaborated with the manual method. However, by having a three-dimensional model and using Revit software, it was also possible obtaining building's perspectives and cuts.

Table 1. Surveyed buildings with the photogrammetric method (Source: Authors).

\begin{tabular}{ccc}
\hline$\#$ & Building Name & Building Classification \\
\hline 1 & Building C & Undergraduate Classrooms \\
2 & Geotechnics Building & Cubicles and Laboratory \\
3 & Renewable Energy Laboratory & Laboratory \\
\hline
\end{tabular}




\subsection{Use of Scanners for Surveying Existing Buildings}

\subsubsection{Evaluation of Scanners}

At the time of the research, two devices were suitable regarding accuracy, entry price and point cloud production cost. The first one was a Faro Freestyle which is a scanner developed by Faro company, which is a world leader in the laser scanner market. The advantage is that it offers one of the best precision available, and its technology is proprietary, including the sensors. The disadvantage is that it requires a connected laptop or high-end Windows tablet (Microsoft Surface Tablet), which limits its operation and mobility, e.g., a single operator needs one hand to support the tablet and the other to support and operate the scanner. It uses two software applications, Faro Scene Capture, which should be installed in the tablet or laptop and it has limited support for processing, displaying and exporting scans [15]. Faro Scene Process is needed for cloud processing and reviewing, and it should be installed in a high-end workstation.

The other device is a DPI- 8 Kit, distributed by the company DotProduct3D. This device is composed of a structured light infrared sensor that connects to a high-performance tablet, which uses the camera to perform a color assignment for recorded points and stereoscopy and the gyroscope to detect the sensor movement. All this is processed in real time by the Phi.3D Software, developed by the company. Its advantage is the independence of a computer since the Tablet is the source of power and viewfinder, which allows greater mobility. Another advantage is that the scanned model and point cloud can be processed and reviewed on the Tablet, without the need for post-processing.

Figure 4 shows a DPI- 8 scanner; this equipment was chosen for this research because it offered better mobility, an immediate process and review of the point cloud, and an affordable price.

\subsubsection{Recommended Techniques for Using the Scanner}

$3 \mathrm{D}$ scanning with the tested device is like video recording. The scanner records what is on the screen and, by coloring the registered areas green and yellow, it is relatively easy and fast to scan the building elements. This device was only used to scan indoors of buildings due to the limitation of becoming "blind" in exteriors because sunlight saturates the infrared sensors of the scanner.
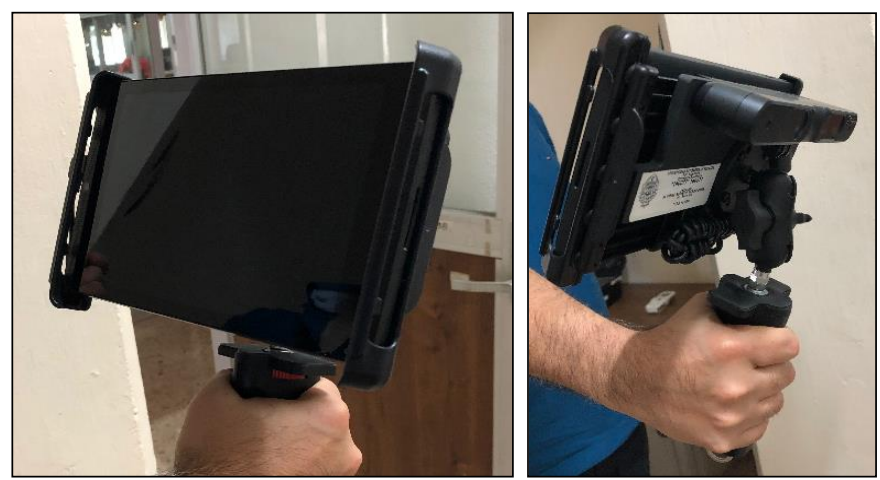

Figure 4. Display of the DPI-8 handheld scanner. 
Despite being very easy scanning a space, during the team's previous practices with the scanner, some problems were found. For example, in the case of smooth walls, the scanner loses scan tracking because there is no texture reference. When this happens, it must resume scanning from one of the nearby points successfully scanned.

When closing the scanning space, sometimes the starting and ending points had a lag. However, this problem was easily solved by using the same label at the beginning and ending points of each scanning process. Labels are symbols that the device's software recognizes and help to align different camera shots of the same space. These symbols are printed on letter-size sheets and pasted using adhesive tape on different places in the space to be scanned. They are extremely useful for adjusting the whole scanning process, to help keep track of the scan in smooth and untextured walls. Also, they are used to join scans of contiguous spaces. These tags are known as "April Tags"; Figure 5 shows an example.

In addition to the "April Tags", there are other labels known as "Targets" that serve to improve scanning accuracy. They are placed in three locations of the space to be scanned, preferably aligned each one to a reference plane (X, Y, Z), and the distance of the centers of a label to the others is measured; this information is entered when scanning, and it serves to adjust scanning scale accuracy. According to the experience obtained through this study, it is concluded that it is highly recommended to use them.

The best approach for scanning according to the results of this research is to start the scan in an "April Tag" nearby junctions of ceiling or floor with walls because these unions are usually a good reference to avoid losing scan track. Then, at a steady scanning rate, follow the entire border until it finishes again in the starting "April Tag". Generally, this process generated a scanned strip of good quality, which contained about $40 \%$ of what the scanned space contains; from there it was easy to fill the spaces that had not yet been scanned. This practice always yielded the best and highest precision results.

\subsubsection{Point Cloud Scaling Using the Manual Scanner}

Point cloud produced by the scanner does not require post-process to be used. It is advisable to clean redundant and excess of information. Afterward, it can be imported into a BIM model-authoring software.
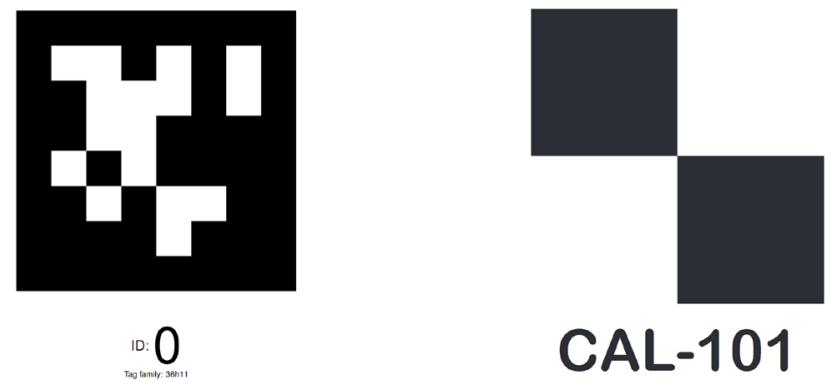

Figure 5. Label example "April Tag" and "Target" for space scanning support (Source: Authors). 


\subsubsection{D Scanner Methodology for Existing Buildings Surveying}

For this stage, like the previous one, teams of two people were formed, consisting of undergraduate students who participated in the project. Surveys of same buildings were carried out as in the photogrammetric method.

Workflow for this technique consisted of the following stages:

- Building spaces scanning.

- Point cloud calibration.

- Model development.

Scanning was performed following the recommendations described in section

2.2.2. The scanner was not used for the exterior of the building, because its infrared sensors become "blind" under sunlight; however, model developing was possible with the information of its interior. The scanner used was the DPI-8 of DotProduct 3D, described in Section 2.2.1.

Point cloud calibration and pruning were done with the Recap 360 software. This scanner produces point clouds at scale. In the same way, scanner aligns the scans of the different building spaces, and in few occasions, it was necessary to make small adjustments to the alignment; when necessary, this alignment was made with Revit.

Also, for model development, Revit was used using the point cloud as a reference. The model floor plan views were created to match the deliverable with those obtained with the manual method. However, as in the photogrammetric method, having a three-dimensional model it was also possible to obtain building perspectives and cuts.

\subsection{Surveying of Building Information by Tape and Distance Meter (Manual)}

For this stage, a team of 4 to 5 students was formed for each of the studied buildings. Each team made the architectural survey of their assigned building, as well as the corresponding documentation, consisting of an architectural plan and elevation of the main facade. Students were trained on how to do it; in the training, the procedures and use of necessary instruments were explained to them. These instruments were a measurement tape and distance meter.

The architectural survey was carried out in the following three stages.

\subsubsection{Preparation phase}

In this stage, teams made recognition of their assigned building, to capture its spatial, volumetric conformation, as well as its dimensions, proportions and the different elevations of its construction site. In this phase, a recommendation to the students was to take photographs (Figure 6) and/or a video of the building, so that this information made the processes of drawing up floor plans and measurement, less difficult. Thus, obstacles were identified as well. In this stage of the survey, general plan sketches, internal distributions, and elevations were also made, which served as reference and expedited measurement process. Sketches were created of with sufficient size to accommodate dimension annotation and 
observations.

\subsubsection{Measurement Phase}

In this stage, teams were organized in such a way that a minimum of 3 people was required, one person to record the measurements and two others to operate the measuring tape, with the help of the mentioned instruments.

Dimensions were taken between axes, columns, walls, windows cubicles, and all the elements that made up each of buildings, as shown in Figure 7.

Laser distance meter was used to measure heights which is an electronic instrument that calculates the distance from the device to the next point to which it points out (see Figure 8).

\subsubsection{Documentation Phase}

Documentation that was requested from the student work teams for each building was a floor plan (see Figure 9) and a sketch for the main facade. For the preparation of the floor plans, obtained measurements in the field were considered (height, width, and length of walls, columns, windows, doors, and accessories). The teams used AutoCAD for drawing these deliverables.

\section{Results}

This section presents the effectiveness of the two tested approaches and the manual surveying method.

It is important to mention that the persons involved in the equipment and software operation for photogrammetry, 3D scanning, generation of the point

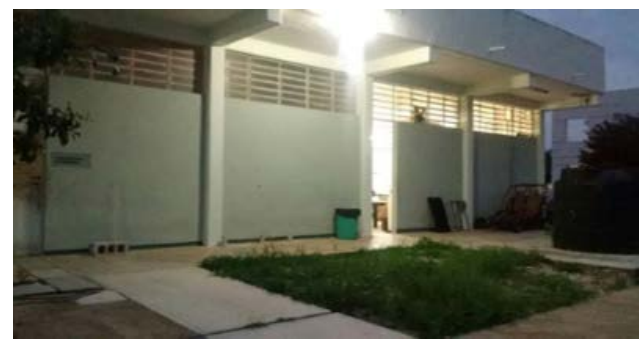

(a)

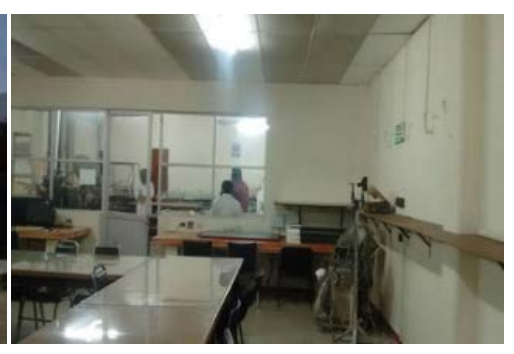

(b)

Figure 6. Outdoors (a) and indoors (b) photos of the Renewable Energy Laboratory building (Source: Authors).
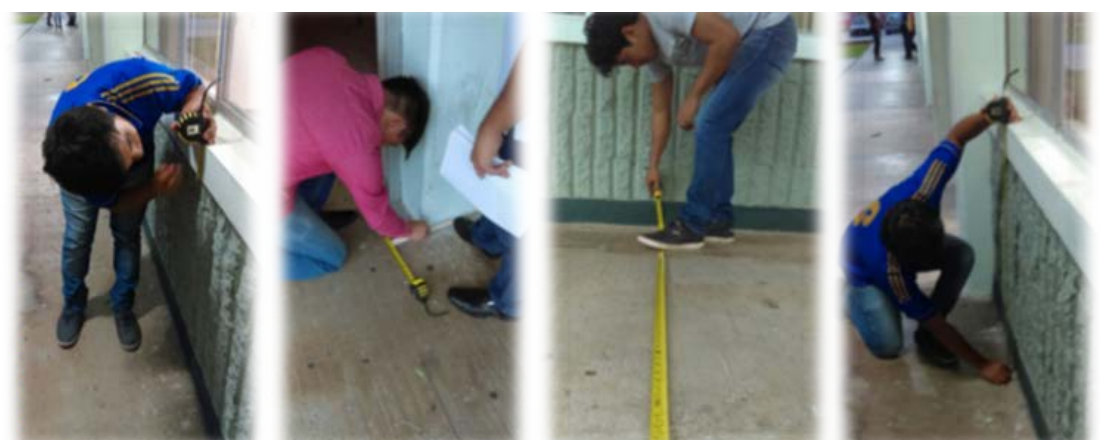

Figure 7. Four examples of using the measuring tape (Source: Authors). 


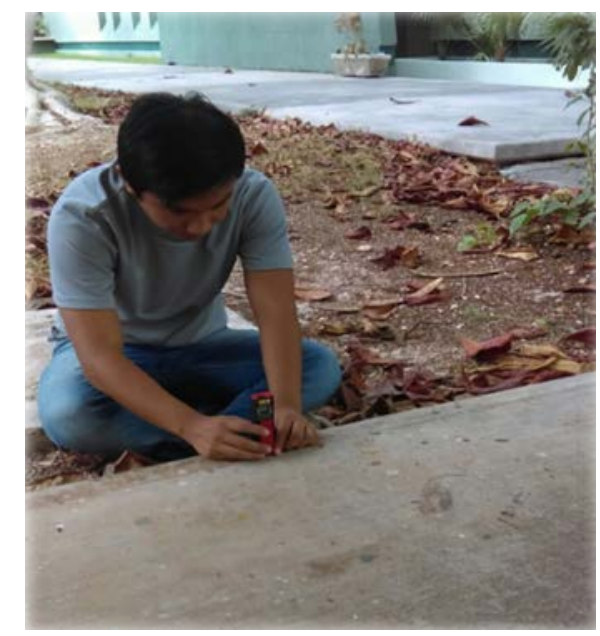

Figure 8. Use of distance meter (Source: Authors).

ARCHITECTURAL FLOOR PLAN

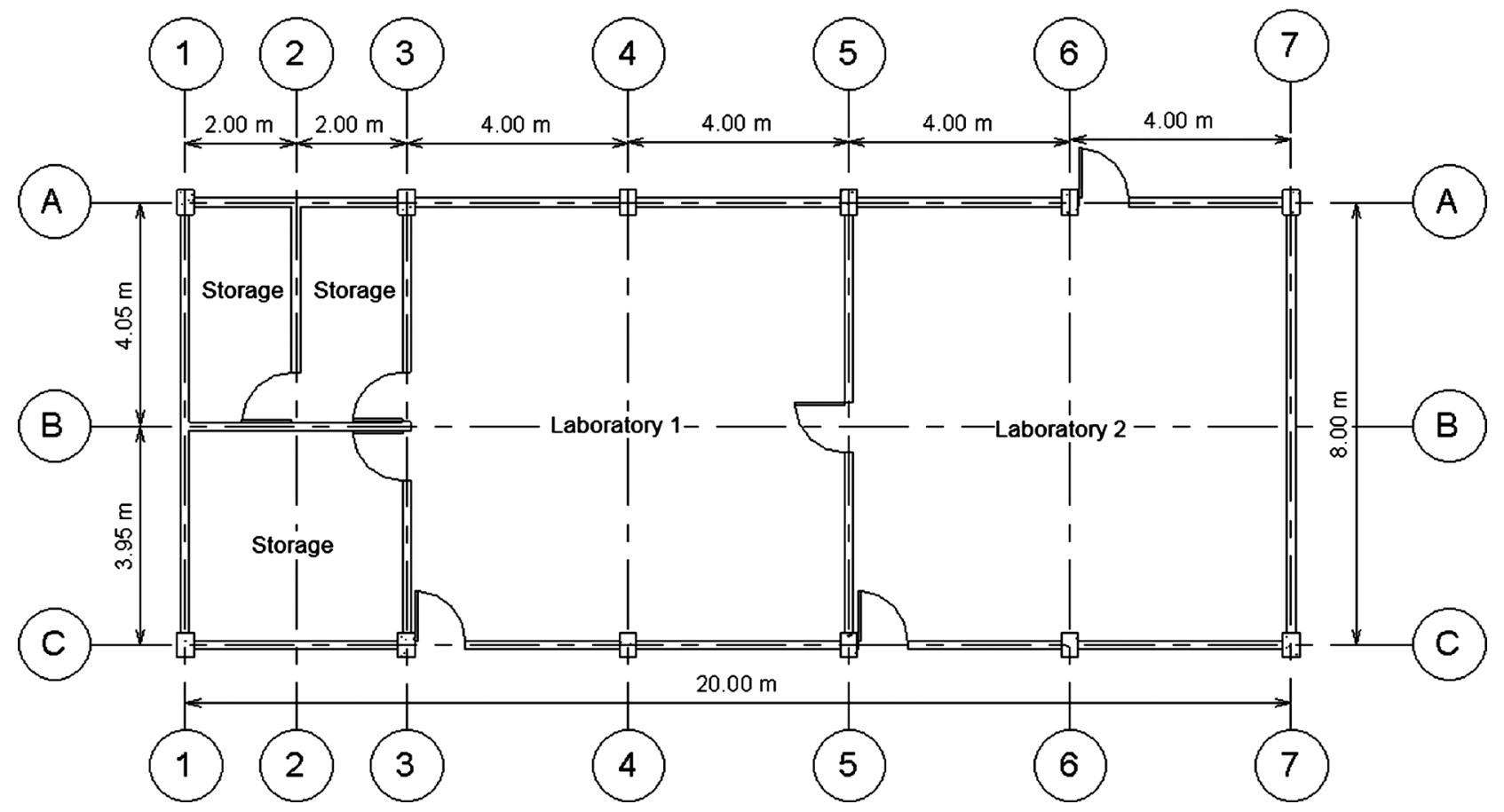

Figure 9. Architectural floor plan (Source: Authors).

cloud, and development of the BIM model, were undergraduate students with no prior experience in such processes; they were trained for conducting these tasks. Students were also in charge of the manual architectural survey; they already had basic knowledge of surveying processes.

\subsection{Photogrammetric Method}

After scanning several designated buildings using possible combinations of cameras and software tools, it was possible to explain in detail advantages and disadvantages of using both photographic equipment and computer applica- 
tions, which can be summarized as follows:

- Regarding the cameras, with all the good results that were obtained, they were even tested with other mobile phones cameras obtaining similar results. When space is restricted, GoPro camera is an excellent choice; if space allows a DSLR or a mobile phone with a good resolution, it produces satisfactory results.

- Regarding the software, if GoPro is used, better results are obtained using Autodesk Recap 360 because it natively supports this camera. The Autodesk Recap 360 resulting point cloud is always usable in comparison with Agisoft PhotoScan, which produces not usable point clouds in most cases. If another type of camera is used, then Agisoft PhotoScan is more efficient in the production of a usable point cloud.

\section{The Efficiency of the Photogrammetric Method}

For accuracy assessment, the error is defined as the average of the absolute difference of the point cloud and the manually measured dimensions divided by the manually measured dimension. This work considers the manual architectural survey as the most accurate of the three methods. The best scanned precision was achieved when using DSLR cameras. For outdoors dimensions, the calculated error was of $0.8 \%$ for buildings with dimensions up to $22 \mathrm{~m}$ in their greater length. For indoors measurements, the resulting error was of $1.3 \%$ in dimensions for rooms up to $6 \mathrm{~m}$ in its longest dimension. Regarding work team productivity, obtained results are listed in Table 2. Figure 10 shows the result of a cloud of points in Renewable Energy Laboratory building.

The average productivity of photographing, processing and calibration phase was $81.84 \mathrm{~m}^{2} / \mathrm{h}$, with a standard deviation of 16.92 .

The average productivity of developing model phase was $259.03 \mathrm{~m}^{2} / \mathrm{h}$, with a standard deviation of 34.21 .

\subsection{Scanner Method}

One of the advantages of the DPI-8 device is that it is capable of scanning chromed metal objects with high reflectivity, a feature that was not possible with photogrammetry.

Table 2. Elapsed times and productivity of the survey using the photogrammetric method (Source: Authors).

\begin{tabular}{|c|c|c|c|c|c|c|c|c|}
\hline \# & $\begin{array}{l}\text { Building } \\
\text { Name }\end{array}$ & $\begin{array}{c}\text { Building } \\
\text { Classification }\end{array}$ & $\begin{array}{l}\text { Num. of } \\
\text { Storeys }\end{array}$ & $\mathrm{m}^{2}$ & $\begin{array}{l}\text { Time elapsed in phases } \\
\text { of taking photographs, } \\
\text { processing, and } \\
\text { calibration (Minutes) }\end{array}$ & $\begin{array}{l}\text { Productivity in phases } \\
\text { taking photographs, } \\
\text { processing, and } \\
\text { calibration }\left(\mathrm{m}^{2} / \mathrm{h}\right)\end{array}$ & $\begin{array}{l}\text { Time elapsed in } \\
\text { the model } \\
\text { development } \\
\text { phase. (Minutes) }\end{array}$ & $\begin{array}{l}\text { The productivity } \\
\text { of the model } \\
\text { development phase } \\
\left(\mathrm{m}^{2} / \mathrm{h}\right)\end{array}$ \\
\hline 1 & Building C & $\begin{array}{c}\text { Undergraduate } \\
\text { classrooms }\end{array}$ & 1 & 456.65 & 279 & 98.20 & 102 & 268.61 \\
\hline 2 & $\begin{array}{l}\text { Geotechnics } \\
\text { Building }\end{array}$ & $\begin{array}{l}\text { Cubicles and } \\
\text { laboratory }\end{array}$ & 1 & 350.00 & 326 & 64.42 & 95 & 221.05 \\
\hline 3 & $\begin{array}{l}\text { Renewable } \\
\text { Energy } \\
\text { Laboratory }\end{array}$ & Laboratory & 1 & 297.00 & 215 & 82.88 & 62 & 287.42 \\
\hline
\end{tabular}




\subsubsection{Efficiency of Scanner Method}

The scanner method was used in rooms with dimensions up to $6 \mathrm{~m}$. The point cloud precision ranged between $0.3 \%$ and $0.6 \%$ of error. Table 3 shows the work team productivity results. Figure 11 shows a point cloud produced with the

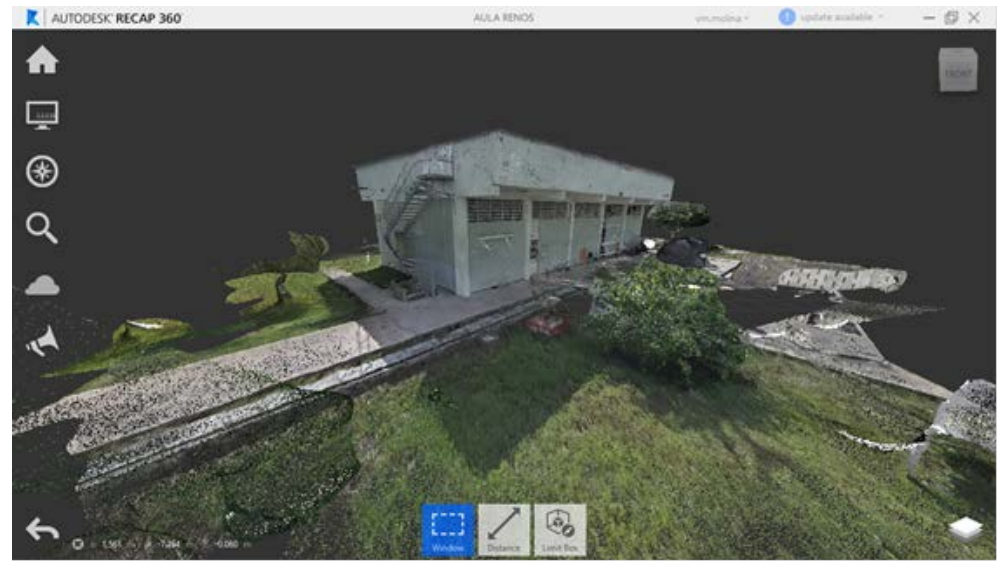

Figure 10. Point cloud of Renewable Energy Laboratory building from photographs with a mobile phone camera (Source: Authors).

Table 3. Elapsed times and productivity of the survey using the scanner method (Source: Authors).

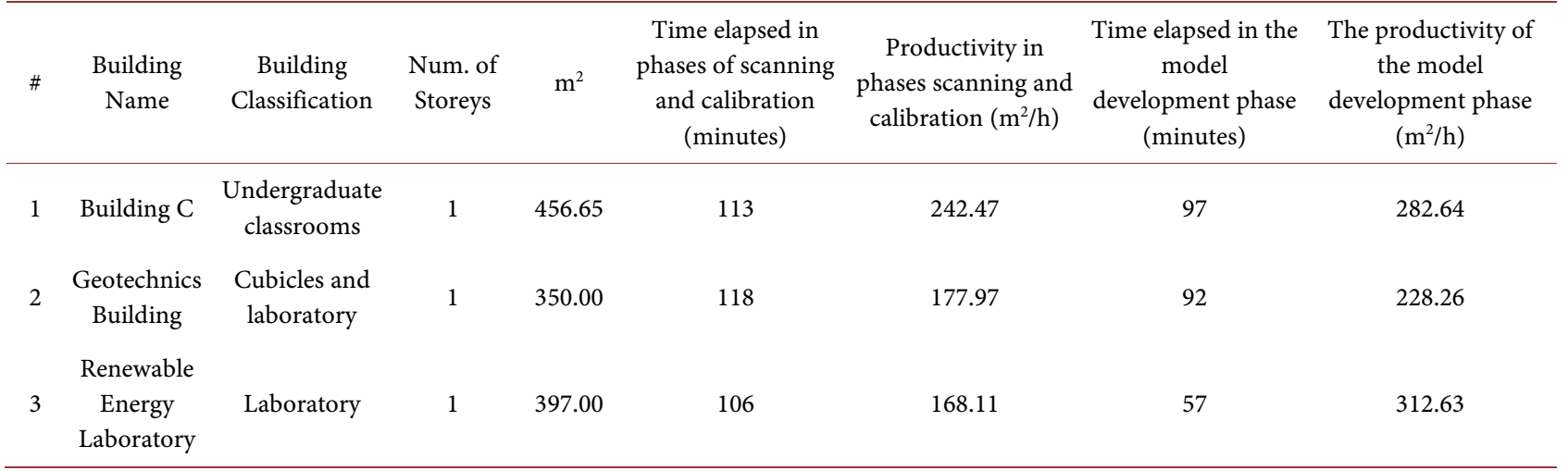

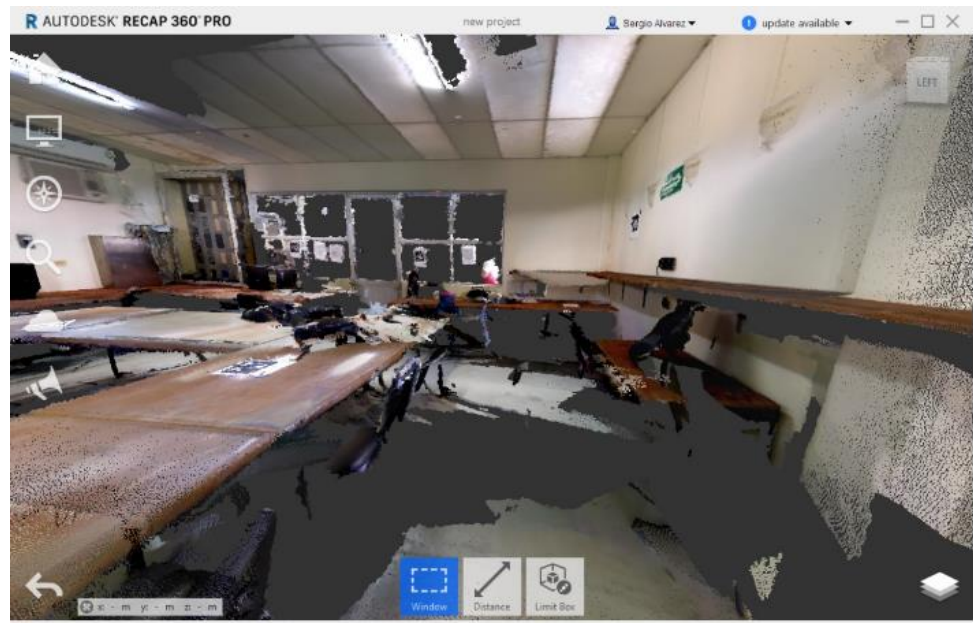

Figure 11. Point cloud inside Renewable Energy Laboratory building produced with a 3D scanner (Source: Authors). 
scanner, inside the Renewable Energy Laboratory building.

The average productivity of scanning and calibration phase was $196.18 \mathrm{~m}^{2} / \mathrm{h}$, with a standard deviation of 40.39 .

The average productivity of developing model phase was $274.45 \mathrm{~m}^{2} / \mathrm{h}$, with a standard deviation of 42.75 .

\subsubsection{The Method with Tape and Distance Meter}

Table 4 shows productivity with the manual method.

The average productivity of preparation and measurement phase was 138.61 $\mathrm{m}^{2} / \mathrm{h}$, with a standard deviation of 76.58 . The average productivity of the documentation phase was $76.91 \mathrm{~m}^{2} / \mathrm{h}$, with a standard deviation of 42.33 . The averages and standard deviations mentioned include data from other buildings that it was also possible to record for the manual survey method.

\section{Discussion}

Table 5 presents a comparison of elapsed times of the three methods, taking the first phase as obtaining dimensions, and second as the creation of deliverables of the process. Although for each method they are identified with different names, they are equivalent.

According to Table 5, the most productive method for obtaining the information necessary to create the deliverable is Manual 3D scanner and the least productive is photogrammetry; on the other hand, the most productive method to generate the deliverable is using the $3 \mathrm{D}$ scanner and the least productive is the manual method.

However, results are presented using a method for the whole building, even

Table 4. Elapsed times and productivity of survey using tape and distance meter (Source: Authors) photogrammetry.

\begin{tabular}{|c|c|c|c|c|c|c|c|c|}
\hline$\#$ & Building Name & $\begin{array}{c}\text { Building } \\
\text { Classification }\end{array}$ & $\begin{array}{l}\text { Num. of } \\
\text { Storeys }\end{array}$ & $\mathrm{m}^{2}$ & $\begin{array}{l}\text { Time elapsed in } \\
\text { preparation and } \\
\text { measurement phases }\end{array}$ & $\begin{array}{c}\text { The productivity of } \\
\text { preparation and } \\
\text { measurement phase }\left(\mathrm{m}^{2} / \mathrm{h}\right)\end{array}$ & $\begin{array}{c}\text { Time elapsed } \\
\text { in the } \\
\text { documentati } \\
\text { on phase }\end{array}$ & $\begin{array}{l}\text { Documentati } \\
\text { on phase } \\
\text { productivity } \\
\qquad\left(\mathrm{m}^{2} / \mathrm{h}\right)\end{array}$ \\
\hline 1 & Building C & $\begin{array}{c}\text { Undergraduate } \\
\text { classrooms }\end{array}$ & 1 & 456.65 & $3 \mathrm{~h}$ & 152.22 & $5 \mathrm{~h} 30 \mathrm{~m}$ & 76.28 \\
\hline 2 & $\begin{array}{l}\text { Geotechnics } \\
\text { Building }\end{array}$ & $\begin{array}{l}\text { Cubicles and } \\
\text { laboratory }\end{array}$ & 1 & 350.00 & $5 \mathrm{~h} 15 \mathrm{~m}$ & 66.67 & --------- & 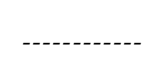 \\
\hline 3 & $\begin{array}{c}\text { Renewable Energy } \\
\text { Laboratory }\end{array}$ & Laboratory & 1 & 297.00 & $3 \mathrm{~h} 20 \mathrm{~m}$ & 83.10 & $4 \mathrm{~h}$ & 74.25 \\
\hline
\end{tabular}

Table 5. Results comparison between the three methods (Source: Authors).

\begin{tabular}{cccc}
\hline Method & $\begin{array}{c}\text { The productivity of The productivity } \\
\text { of obtaining information phase } \\
\left(\mathrm{m}^{2} / \mathrm{h}\right)\end{array}$ & $\begin{array}{c}\text { Standard deviation } \\
\text { information acquisition } \\
\text { phase }\end{array}$ & $\begin{array}{c}\text { The average productivity of } \\
\text { deliverable creation phase } \\
\left(\mathrm{m}^{2} / \mathrm{h}\right)\end{array}$ \\
$\begin{array}{c}\text { The standard deviation } \\
\text { of deliverable creation } \\
\text { phase }\end{array}$ & 31.84 & 34.21 & 259.03 \\
Photogrammetry & 196.18 & 40.39 & 274.45 \\
Manual 3D Scanner & 138.61 & 76.58 & 76.91 \\
\hline
\end{tabular}


knowing that in some situations are unfavorable for one method or another. For example, in the case of using the manual scanner it was not possible to scan the building exterior; as the emphasis of these surveys was on the architectural elements, it was possible to develop a BIM model without having specific information from the building exterior. However, for maintenance, it is necessary to have facilities information; in this case, it will be necessary to complement the information using another method to obtain data from the building exterior.

An important aspect to mention is that in case of rooms and cubicles, where conditions were very unfavorable for photogrammetry method due to a large amount of glass and walls with little texture, the most convenient method was the manual one.

The scanner method presented the most efficient results. However, there are some cases, like the one described above, where the manual method had better results than the scanner method. Where scanner represents, by far the best option is in case of mechanical rooms or laboratories, where space is limited, and some elements that are required to be included in the model for maintenance are so large, that the manual method is extremely complex and takes much time.

Photogrammetry was the most unfavorable method for obtaining building information due to the processing time of photographs, which represents $63 \%$ of the elapsed time. However, its advantages are evident when it comes to surveying building exteriors, especially those of considerable height; in these cases, the method offers easy access and greater safety. Also, in case of not having a 3D scanner for surveying mechanical rooms or cubicles having a lot of equipment, installations or furniture, photogrammetry offers more efficiency than the manual method.

The manual method is the most unfavorable when developing and processing the model deliverables. The main reason is that, when developing the model, it is very usual to find out that there are inconsistencies or lack of information and it is necessary to pay a visit back to the building to corroborate the missing information.

\section{Conclusions}

In this research, three different approaches for gathering geometric and layout information of existing buildings for operation and maintenance purposes were assessed: photogrammetry, 3D scanning, and manual architectural survey. Each approach presented advantages and limitations, some of them showed higher efficiency while others showed technological limitations than inhibited its use, depending on the context.

These conclusions are based on the equipment and software tools used in this research. For different equipment and software tools, the results may vary depending on their characteristics.

The main conclusion is that a combination of several methods is advisable to be used for obtaining geometrical information of existing buildings: 
- For outdoors, the recommended option from the quantitative (productivity) and qualitative (quantity, flexibility, and clarity of information) point of view, photogrammetry is the best method to use. Actually, the 3D scanner does not work in exteriors under direct sunlight, because of its infrared sensors.

- For indoors with simple geometries and few installations that need to be recorded, the most efficient and suitable method is the manual architectural survey.

- For indoor spaces used as mechanical rooms or places with many installations, equipment, or obstacles, the 3D scanner is the best option, in regard to the overall performance. If there is no access to a $3 \mathrm{D}$ scanner due to financial limitations, photogrammetry is the second-best option; even though the manual method has the best accuracy, it has significant lower productivity and limitations in crowded spaces as the mechanical rooms.

\section{Acknowledgements}

This research was granted by the Programa para el Desarrollo Profesional Docente (PRODEP), Ministry of Education-Mexico.

We thank the students (from the undergraduate program of Civil Engineering-School of Engineering at UADY) for their support in this research.

\section{Conflicts of Interest}

The authors declare no conflicts of interest regarding the publication of this paper.

\section{References}

[1] Fuller, S. (2010) Life-Cycle Cost Analysis (LCAA). National Institute of Building Sciences. http://www.wbdg.org/resources/lcca.php

[2] Wiggins, J.M. (2010) Facilities Manager's Desk Reference. Wiley-Blackwell, USA. https://doi.org/10.1002/9781444320466

[3] Quintero, M., Solano, C. and Pandales, C. (2013) La Degradación y el Mantenimiento en las Obras de Edificación: Estudio de Caso Institución Educativa Antonio Derka Santo Domingo. Tesis Inedita, Universidad de Medellin, Colombia.

[4] Amarilla, B. (1989) Los Costos de Mantenimiento de Edificios en Países en Vías de Desarrollo. Informes de la Construcción, Vol. 41 n. ${ }^{\circ} 404$, noviembre/diciembre.

[5] Goedert, J.D. and Meadati, P. (2008) Integrating Construction Process Documentation into Building Information Modeling. Journal of Construction Engineering and Management, 134, 509-516. https://doi.org/10.1061/(ASCE)0733-9364(2008)134:7(509)

[6] Sullivan, G.P., Pugh, R., Melendez, A.P. and Hunt, W.D. (2010) Operations \& Maintenance.

[7] Teicholz, P. (2013) BIM for Facility Managers. John Wiley \& Sons, Inc., Hoboken, New Jersey.

[8] East, E.W. (2007) Construction Operations Building Information Exchange (COBIE): Requirements Definition and Pilot Implementation Standard. https://doi.org/10.21236/ADA491899 
[9] Baker, J., et al. (2013) UMass Medical School (UMMS). Conference Presentation in the Event Building Information Modeling (BIM): From Concept to Substantial Completion (and Beyond). Worcester, MA, 17 January 2013, 3.

[10] Almagro, A. (2004) Levantamiento Arquitectónico, Granada University.

[11] Autodesk Knowledge Network. https://knowledge.autodesk.com/es/support/autocad/learn-explore/caas/CloudHelp /cloudhelp/2017/ESP/AutoCAD-Core/files/GUID-C0C610D0-9784-4E87-A857-F17 F1F7FEEBE-htm.html

[12] Luhman, T., Robson, S., Kyle, S. and Boehm, J. (2011) Close-Range Photogrammetry and 3D Imaging. Revised Edition, De Gruyter, USA.

[13] DotProduct3D (2015) Electronic Publication. https://www.dotproduct3d.com/dpi8x.html

[14] Agisoft (2016) Agisoft PhotoScan User Manual, Standard Edition Version 1.3, Agisoft LCC.

[15] FARO (2017) Faro Freesyle 3D and Software User Manual. FARO Technologies Inc. 